\title{
Choroid plexus trophic factors in the developing and adult brain
}

\author{
Karen Arnaud ${ }^{1,2}$, Ariel A. Di Nardo $(\bowtie)^{1}$ \\ ${ }^{1}$ Center for Interdisciplinary Research in Biology (CIRB), CNRS UMR 7241/INSERM U1050, Labex Memolife, Collège de France, \\ 75231 Paris, France \\ ${ }^{2}$ Université Pierre et Marie Curie, Paris VI, Paris, France \\ (C) Higher Education Press and Springer-Verlag Berlin Heidelberg 2016
}

\begin{abstract}
The choroid plexus (CP), localized in brain ventricles, is the major source of cerebrospinal fluid (CSF) and participates in the blood-CSF barrier. It is essential for brain immunosurveillance and the clearance of toxics, and for brain development and activity. Indeed, the CP secretes a large variety of trophic factors in the CSF that impact the entire brain. These factors are mainly implicated in neurogenesis, but also in the maintenance of brain functions and the vasculature. In this mini-review, we provide an overview of the various trophic factors secreted by the CP in the CSF, and describe their roles in the developing, adult and diseased brain.
\end{abstract}

Keywords choroid plexus, trophic factors, CSF, neurogenesis, development, adult brain

\section{Introduction}

The choroid plexus (CP) is leaf-like structure suspended in the cerebrospinal fluid (CSF) and attached to the ependyma by a thin stalk. It is a highly vascularized structure localized in the lateral, third and fourth ventricles of the brain. CP development and structure are highly conserved between species (Dziegielewska et al., 2001). Its development begins at early stage embryogenesis after neural tube closure, when the hindbrain $\mathrm{CP}$ in the 4 th ventricle first appears, followed by the telencephalic $\mathrm{CP}$ in the lateral ventricles and the diencephalic CP in the 3rd ventricles. Two cells types are implicated in the formation of CPs: neuroectoderm cells for the CP epithelium formation; and the mesoderm for the formation of the CP stroma (Strazielle et al., 2005; Liddelow, 2015; Lun et al., 2015). The developing CP might also contain neural progenitor-like cells as precursors of neurons observed later in CP. These cells could assist CP formation during embryogenesis by providing a neural regulatory network that modulates CP functions (Itokazu et al., 2006; Huang et al., 2011; Prasongchean et al., 2015). The development, formation and specification of CPs is guided

Received January 30, 2016; accepted April 25, 2016

Correspondence: Ariel A. Di Nardo

E-mail: ariel.dinardo@college-de-france.fr by specific growth and transcription factors (Johansson, 2014; Liddelow, 2015).

The CP is the principal source of CSF in the brain (Spector et al., 2015a) and is responsible for the maintenance of brain homeostasis through regulation of fluid and electrolyte balance in the central nervous system (CNS). The composition of CSF is very similar to plasma and is secreted via an active mechanism by choroidal cells. CP maintains CSF composition by filtration and by controlling solute and water movements across the epithelium (Damkier et al., 2013). The $\mathrm{CP}$ is also part of the brain barrier that forms a blood-CSF barrier implicated in CNS immunosurveillance (Engelhardt et al., 2001; Meeker et al., 2012; Kunis et al., 2013). It eliminates toxic peptides from the brain via various transporters: CP is a sort of "kidney" in the brain (Spector and Johanson, 2010; Saunders et al., 2013; Spector et al., 2015b). Also, many functions are attributed to the CSF, such as the regulation of intracranial pressure and brain volume, nutrient transport, drainage, immune regulation, and the transport of proteins and peptides coming from the CP (Chodobski and Szmydynger-Chodobska, 2001; Redzic and Segal, 2004; Strazielle et al., 2005; Spector et al., 2015b). Indeed, the $\mathrm{CP}$ secretes many proteins and peptides in the CSF, such as hormones, growth factors, homeoproteins, etc, which can easily diffuse throughout the brain (Johanson et al., 2011b) and affect both developing and adult brain. In this short review, we will focus on growth factors and 
neurotrophic factors expressed by the $\mathrm{CP}$ and explore their implications in the developing and adult brain, in health and disease.

\section{Impact of choroid plexus trophic factors in the developing brain}

During early brain development, the ventricles occupy the majority of the cranial volume and are filled with circulating CSF that originates from choroid epithelial cells. This fluid contains many proteins that regulate brain development and neurogenesis by signaling and feeding rapidly dividing progenitors along the ventricular walls (Zappaterra and Lehtinen, 2012; Falcão et al., 2012; Gato et al., 2014). Upon secretion into the ventricle, molecules from the $\mathrm{CP}$ are conveyed by CSF bulk flow to the various regions of the developing brain (Miyan et al., 2003). Also, certain proteins secreted by CP cells impact the development and maintenance of the $\mathrm{CP}$ itself via autocrine signaling. Among these proteins that orchestrate proper brain development are numerous growth factors, neurotrophic factors and morphogens (Fig. 1).

The major growth factors found in embryonic CSF include transforming growth factor (TGF), insulin growth factor (IGF) and fibroblast growth factor (FGF). The TGF- $\beta$ family, including bone morphogenic proteins (BMPs) and the growth differentiation factors (GDFs), are involved in the developing brain by promoting cell growth and proliferation, and inhibiting neuronal death (Falk et al., 2008). BMP7 has recently been shown to regulate the survival, proliferation and neurogenic properties of neural precursor cells during brain corticogenesis (Segklia et al., 2012). BMP7 from CP also directly attenuates the differentiation of the adjacent neural progenitors, maintaining a pool of progenitors (Krizhanovsky and Ben-Arie, 2006). TGF- $\beta 2$ and TGF- $\beta 3$ are important regulators of neuron survival, while GDF-15 is important for developing and injured neurons, via its protective action against death (Strelau et al., 2000). BMPs are also important for the specification of CP epithelium. The inhibition of BMP signaling can result the absence of CP (Hébert et al., 2002), whereas BMP4 alone is sufficient to induce $\mathrm{CP}$ epithelial cells from embryonic stem cell-derived neuroepithelial progenitors (Watanabe et al., 2012).

IGF acts on the developing $\mathrm{CP}$ for its function and maintenance (Nilsson et al., 1996) and is expressed and secreted by CP cells (Salehi et al., 2009; Lehtinen et al., 2011). During development, IGF promotes the proliferation, migration and differentiation of immature glial and neuronal cells (Lehtinen et al., 2011; Ziegler et al., 2012).

In early CP development, FGF expression, particularly FGF2, modulates gene expression and activity, suggesting that FGF signaling maintains $\mathrm{CP}$ integrity and function (Greenwood et al., 2008). Secreted FGF2 has also been shown to have a role in the developing brain by regulating cell proliferation/neurogenesis and corticogenesis (Vaccarino et al., 1999; Mashayekhi et al., 2011).

Neurotrophic factors are also highly expressed in the developing brain, during the phase of neurogenesis (Maisonpierre et al., 1990). Nerve growth factor (NGF) and neurotrophins (NT) are all expressed and secreted by the $\mathrm{CP}$ in the CSF. NGF, NT3 and NT4 promote proliferation, survival, and neurochemical differentiation of selected neuronal populations in the CNS (Xia et al., 2000; Das et al., 2001; Mashayekhi et al., 2009).

The CP secretes other proteins and molecules that impact brain patterning and activity. Sonic hedgehog (Shh) contributes to the $\mathrm{CP}$ development by acting on the progenitor pool of CP epithelial cells, and permitting CP expansion (Huang et al., 2009). Shh has also been shown to coordinate the vascular development in CP (Nielsen and Dymecki, 2010). Transthyretin (TTR), also known as prealbumin, is secreted by the $\mathrm{CP}$ and carries the thyroid hormone thyroxin and retinol binding protein. TTR and thyroid hormones have an important role in regulating brain expansion and growth (Alshehri et al., 2015). Some studies have shown that CP expresses $\gamma$-aminobutyric acid (GABA) and glutamic acid decarboxylase 65 (GAD65), suggesting a production of nonneuronal GABA which can modulate the properties of neural progenitors in the developing cortex (Tochitani and Kondo, 2013).

\section{Impact of choroid plexus trophic factors in the adult brain}

In the adult brain, while the ventricles now occupy very little volume, the $\mathrm{CP}$ continues to secrete growth and transcription factors in the CSF, including FGF, epithelial growth factor (EGF), TGF- $\beta$, platelet derived growth factor (PDGF), IGF, vascular endothelial growth factor (VEGF), and the homeoprotein Otx2 (Fig. 1). Many of these factors are implicated in either adult neurogenesis, plasticity, cognition or angiogenesis (Marques et al., 2011; Falcão et al., 2012; Stolp and Molnár, 2015). Indeed, the CSF can impact the entire brain, due to its capacity to diffuse around the brain and in the parenchyma, along vessels (Iliff et al., 2012; Brinker et al., 2014).

FGF2 injected or infused in the CSF has been shown to increase adult neurogenesis in the subventricular zone (SVZ) and the dentate gyrus (Wagner et al., 1999; Cheng et al., 2002). FGF2 and EGF also maintain neural niche architecture and cell lineage progression (Jin et al., 2003). EGF, infused in the ventricle, increases the proliferation of progenitors cells in the SVZ, and induces their migration and differentiation (Craig et al., 1996; Doetsch et al., 2002).

PDGF is implicated in the maintenance of adult cell types. There is evidence that PDGF contributes to the differentiation 


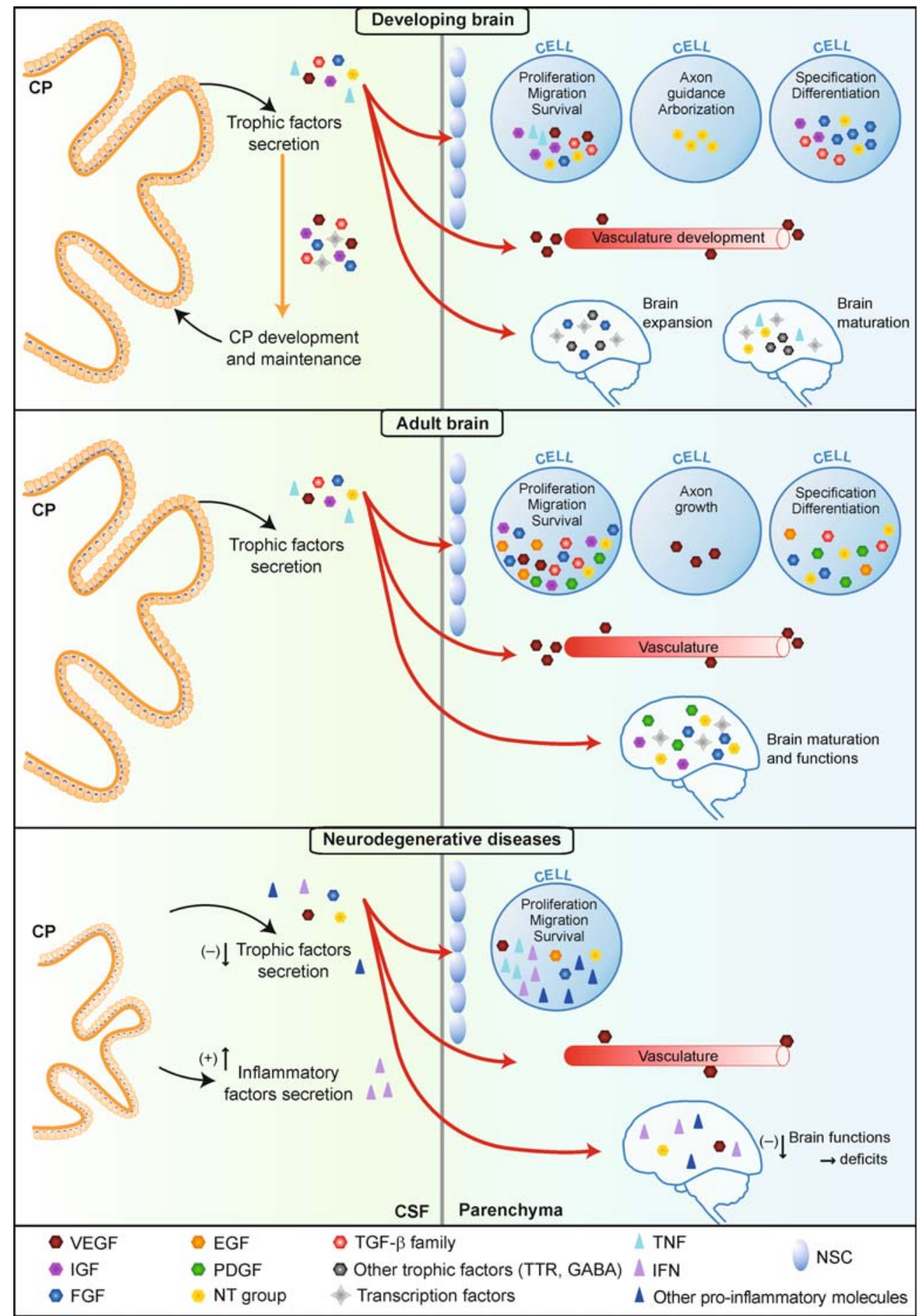

Figure 1 Secretion and roles of trophic factors in the developing and adult brain. The choroid plexus (CP) secretes many trophic factors that impact the developing and adult brain, in health and in disease. During development (top panel), trophic factors guide brain formation through their roles in neurogenesis, vasculature development and brain expansion/maturation. In the adult brain (middle panel), the $\mathrm{CP}$ continues to secrete trophic factors that impact and maintain adult neurogenesis and brain maturation/function. In some diseases (bottom panel), such as those involving neurodegeneration, the $\mathrm{CP}$ atrophies and/or trophic factor secretion is altered. These changes can lead to neuroinflammation, impaired neurogenesis, and compromised vasculature that ultimately result in brain deficits. CP: choroid plexus, CSF: cerebrospinal fluid, VEGF: vascular endothelial growth factor, IGF: insulin growth factor, FGF: fibroblast growth factor, EGF: epithelial growth factor, PDGF: platelet-derived growth factor, NT: neurotrophins, TGF: transforming growth factor, TNF: tumor necrosis factor, IFN: interferons, NSC: neural stem cells. 
of oligodendrocytes in adulthood, and increases proliferation in SVZ (Jackson et al., 2006). SVZ progenitors express PDGF receptors and increase proliferation in response to PDGF signaling (Moore et al., 2014).

In adult brain, VEGF directly regulates the proliferation of adult stem cells, and promotes cell survival and axonal outgrowth (Schänzer et al., 2004; Mackenzie and Ruhrberg, 2012). VEGF is also implicated in the maintenance of CP in adult brain by sustaining normal vasculature (Maharaj et al., 2008). It also affects the proliferation, growth and migration of cells by helping to form angiogenic niches important for neurogenesis, and by acting directly on cells to promote proliferation (Jin et al., 2002; Ruiz de Almodovar et al., 2010; Licht et al., 2010; Mackenzie and Ruhrberg, 2012).

IGF-II promotes the self-renewal of neural progenitors/ stem cells (Ziegler et al., 2012, 2015), and the IGF family has been shown to stimulate neurogenesis and protect cells against injury (Ziegler et al., 2015). IGF also enhances memory by its neurotrophic action on glutamatergic synapses, within hippocampal circuits (Werner and LeRoith, 2014). However, Igf2 levels are greatly reduced in the adult compared to embryonic CSF (Lehtinen et al., 2011). This same study also showed that several BMPs continue to be expressed in adult CP and retain similar CSF activity (Lehtinen et al., 2011).

Neurotrophic factors have a reduced role in adult CSF. Brain-derived neurotrophic factor (BDNF) can increase adult proliferation and cell survival (Pencea et al., 2001; Binder and Scharfman, 2004), while NT3 is implicated in the quiescence and long-term maintenance of adult stem cells (Delgado et al., 2014). BDNF also appears essential for molecular mechanisms of synaptic plasticity (Binder and Scharfman, 2004; Budni et al., 2015).

Others molecules secreted by the CP in adulthood that are implicated in cell proliferation, self-renewal, survival, and migration include Wnt, Shh, ephrins, semaphorins, Slits, and Robo (Falcão et al., 2012). Transcription factors have also been found in CSF. The Otx 2 homeoprotein is secreted by CP in postnatal CSF and accumulates in cortical interneurons to help regulate the timing of periods of hightened circuit plasticity shaped by sensory experience (Spatazza et al., 2013).

\section{Impact of choroid plexus trophic factors in aging and diseases}

Aging impacts CP: the secretion of CSF is reduced and the production of growth factors decreases (Fig. 1) (Redzic et al., 2005; Chen et al., 2012). CP cells themselves are impacted, with morphological and metabolism modifications, and decreased capacity of neuroprotection. Brain permeability can increase with age, due to attenuated $\mathrm{CP}$ barrier, potentially resulting in the entry of inflammatory and toxic molecules in the brain. CSF turnover is modified, resulting in reduced ability to clear proteins from CSF, which can lead to an accumulation of toxic molecules in the aged brain (Preston, 2001; Emerich et al., 2005).

Furthermore, aging is accompanied by reduced production of growth factors, leading to a decrease in adult neurogenesis (Emerich et al., 2004). However, treatment with growth factors during aging could partially revitalize neurogenesis: as CP cells produce a huge quantity of IGF, which is important for neurogenesis and cell turnover, aging $\mathrm{CP}$ could have significant consequence for tissue repair and brain functioning. IGF-1 supplementation can reverse cognitive deficits induced by aging, and can restore normal hippocampal activities (Ashpole et al., 2015). Growth Hormone (GH) has been shown to have the same effect on aging brain (Ashpole et al., 2015). With age, the production of BDNF, NGF and GDNF is modified, resulting in reduced neuronal survival and neurogenesis eventually leading to cognitive impairment (Budni et al., 2015). On the other hand, CP produces new molecules during aging, such as interferon type I (IFN-I), whereas IFN-II production decreases. Changes in IFN levels lead to modified brain function, such as cognitive deficits, hippocampal dysfunctions, neuroinflammation, and decreased neurogenesis (Baruch et al., 2014).

Aging is strongly associated with Alzheimer's disease (AD), the most common neurodegenerative disease. $\mathrm{AD}$ is characterized by cognitive deficits, memory loss and neuronal loss, and is linked to modifications in $\mathrm{CP}$ functions. In $\mathrm{AD}$, CP can have an altered structure (Serot et al., 1997, 2001). It normally has a role in the clearance of amyloid fragments, a hallmark of $\mathrm{AD}$, but with disease progression, this $\mathrm{CP}$ function is altered and the clearance becomes incomplete (González-Marrero et al., 2015). The barrier and "kidney" functions of CP appear to be less efficient. This dysfunction is associated with a reduction in trophic factor production, leading to reduced neuroprotection against $\mathrm{AD}$ hallmarks (Krzyzanowska and Carro, 2012). Certain trophic factors can help the clearance of toxic peptides, such as FGF2 and IGF-1 (Johanson et al., 2004; Carro et al., 2006). But with the progression of $\mathrm{AD}$, a vicious circle appears: low levels of trophic factors induce clearance deficits, which leads to a decrease in factor secretion by the $\mathrm{CP}$. The production of BDNF, NGF and GDF is also modified in compensation during AD: in early stages their concentrations increase, whereas in later stages, they are decreased. In later stages, these modifications probably encourage neuronal loss and memory deficits (Budni et al., 2015; Forlenza et al., 2015). Neuroinflammation is present throughout all AD stages. In early stages, IFN-I, IFN-II and TNF- $\alpha$ levels contribute to neuroprotection by increasing the migration of new cells in the brain (Ben-Hur et al., 2003). But in later stages, IFN-I and IFN-II CSF levels are increased, leading to cell death, suggesting a role in the development of AD pathology (Mesquita et al., 2015).

In other neurodegenerative diseases, CSF trophic factors are also modified. In amyotrophic lateral sclerosis (ALS), 
FGF is increased in the CSF and serum of patients, possibly as a compensation phenomenon for protection against cell apoptosis and neuronal loss (Gong et al., 2015). In AD, ALS and Huntington's disease (HD), modified VEGF levels lead to vascular and neuroprotection impairments (Storkebaum and Carmeliet, 2004). In ALS, it has been shown that altered VEGF levels are indicative of the activation of compensatory responses, which may reflect the disease progression (Gao et al., 2014).

Neuroinflammation is often associated with neurodegenerative diseases. Accordingly, many inflammatory factors, which could also act as neurotrophic factors, are expressed. Increases in IFN-I, IFN-II and TNF- $\alpha$ levels are also changed: they are linked to neurodegeneration pathways in Parkinson's disease (PD), ALS, multiple sclerosis (MS), while contributing to neuroinflammation (McCoy and Tansey, 2008). Other cytokines and pro-inflammatory proteins are also released by the CP, such as CXCL12 and IL1- $\beta$, and have been shown to decrease adult neurogenesis as a consequence of brain inflammation (Stolp and Molnár, 2015).

The secretion of trophic factors can also be regulated during brain injury, such as stroke. During such an event, CP is altered and the barrier can become compromised. However, $\mathrm{CP}$ can react to protect the brain against the lesion/ischemia and to induce brain regeneration/repair. $\mathrm{CP}$ expression of trophic factors, such as IGF-II, EGF, NGF, GDNF, BDNF, VEGF, and TNF, are implicated in the stimulation of adult neurogenesis, angiogenesis and neuroprotection/cell survival (Johanson et al., 2011a; Zappaterra and Lehtinen, 2012). CP cells have also been implicated directly in tissue regeneration, acting as progenitor cells in injured brain (Li et al., 2002).

Under stress conditions, trophic factor levels are modified in the CSF, owing to altered CP secretion and structure, and might be linked to psychiatric disorders. In major depressive disorder (MDD), modified expression of FGF family factors alter hippocampal functions pertaining to mood and emotions (Aurbach et al., 2015). However, another recent study found no difference in $\mathrm{CP}$ growth factor production in MDD patients (Turner et al., 2014), other than a decrease in TGF- $\beta$. It has also been shown that stress can modify BDNF, IGF1, TNF- $\alpha$ and IL1- $\beta$ production/expression in CP (Sathyanesan et al., 2012). In bipolar disorder (BD), BDNF is decreased, with implications in the depression or "active" phases, possibly linked to its role in synaptic function and memory consolidation (Pillai et al., 2010; Rabie et al., 2014). The levels of NGF, BNDF, NT4 and NT5, GDNF, IGF1 and VEGF can be modified during different disease stages and with varying outcomes for BD pathology (Scola and Andreazza, 2015).

\section{Outlook}

The CP secretes many different trophic factors, important in the developing and adult brain. These factors act in the normal brain, but they are also implicated and modified in many diseases. The potential therapeutic effect of $\mathrm{CP}$ cells has not escaped attention, and their transplantation in the diseased brain has been envisioned. The CP is itself a potentially powerful therapeutic target, as it provides a means of suppressing or activating trophic factor levels throughout the brain.

\section{Compliance with ethics guidelines}

K. Arnaud and A. A. Di Nardo declare they have no conflict of interest. This article does not contain studies with human or animal subjects performed by the authors.

\section{References}

Alshehri B, D’Souza D G, Lee J Y, Petratos S, Richardson S J (2015). The diversity of mechanisms influenced by transthyretin in neurobiology: development, disease and endocrine disruption. J Neuroendocrinol, 27(5): 303-323

Ashpole N M, Sanders J E, Hodges E L, Yan H, Sonntag W E (2015). Growth hormone, insulin-like growth factor-1 and the aging brain. Exp Gerontol, 68: 76-81

Aurbach E L, Inui E G, Turner C A, Hagenauer M H, Prater K E, Li J Z, Absher D, Shah N, Blandino PJr, Bunney W E, Myers R M, Barchas J D, Schatzberg A F, Watson S JJr, Akil H (2015). Fibroblast growth factor 9 is a novel modulator of negative affect. Proc Natl Acad Sci USA, 112(38): 11953-11958

Baruch K, Deczkowska A, David E, Castellano J M, Miller O, Kertser A, Berkutzki T, Barnett-Itzhaki Z, Bezalel D, Wyss-Coray T, Amit I, Schwartz M (2014). Aging. Aging-induced type I interferon response at the choroid plexus negatively affects brain function. Science, 346(6205): 89-93

Ben-Hur T, Ben-Menachem O, Furer V, Einstein O, Mizrachi-Kol R, Grigoriadis N (2003). Effects of proinflammatory cytokines on the growth, fate, and motility of multipotential neural precursor cells. Mol Cell Neurosci, 24(3): 623-631

Binder D K, Scharfman H E (2004). Brain-derived neurotrophic factor. Growth Factors, 22(3): 123-131

Brinker T, Stopa E, Morrison J, Klinge P (2014). A new look at cerebrospinal fluid circulation. Fluids Barriers CNS, 11(1): 10

Budni J, Bellettini-Santos T, Mina F, Garcez M L, Zugno A I (2015). The involvement of BDNF, NGF and GDNF in aging and Alzheimer's disease. Aging Dis, 6(5): 331-341

Carro E, Trejo J L, Spuch C, Bohl D, Heard J M, Torres-Aleman I (2006). Blockade of the insulin-like growth factor I receptor in the choroid plexus originates Alzheimer's-like neuropathology in rodents: new cues into the human disease? Neurobiol Aging, 27 (11): 1618-1631

Chen C P C, Chen R L, Preston J E (2012). The influence of ageing in the cerebrospinal fluid concentrations of proteins that are derived from the choroid plexus, brain, and plasma. Exp Gerontol, 47(4): 323-328

Cheng Y, Black I B, DiCicco-Bloom E (2002). Hippocampal granule neuron production and population size are regulated by levels of bFGF. Eur J Neurosci, 15(1): 3-12 
Chodobski A, Szmydynger-Chodobska J (2001). Choroid plexus: target for polypeptides and site of their synthesis. Microsc Res Tech, 52(1): $65-82$

Craig C G, Tropepe V, Morshead C M, Reynolds B A, Weiss S, van der Kooy D (1996). In vivo growth factor expansion of endogenous subependymal neural precursor cell populations in the adult mouse brain. J Neurosci, 16(8): 2649-2658

Damkier H H, Brown P D, Praetorius J (2013). Cerebrospinal fluid secretion by the choroid plexus. Physiol Rev, 93(4): 1847-1892

Das K P, Chao S L, White L D, Haines W T, Harry G J, Tilson H A, Barone SJr (2001). Differential patterns of nerve growth factor, brain-derived neurotrophic factor and neurotrophin-3 mRNA and protein levels in developing regions of rat brain. Neuroscience, 103 (3): 739-761

Delgado A C, Ferrón S R, Vicente D, Porlan E, Perez-Villalba A, Trujillo C M, D’Ocón P, Fariñas I (2014). Endothelial NT-3 delivered by vasculature and CSF promotes quiescence of subependymal neural stem cells through nitric oxide induction. Neuron, 83(3): 572-585

Doetsch F, Petreanu L, Caille I, Garcia-Verdugo J M, Alvarez-Buylla A (2002). EGF converts transit-amplifying neurogenic precursors in the adult brain into multipotent stem cells. Neuron, 36(6): 10211034

Dziegielewska K M, Ek J, Habgood M D, Saunders N R (2001). Development of the choroid plexus. Microsc Res Tech, 52(1): 5-20

Emerich D F, Skinner S J M, Borlongan C V, Vasconcellos A V, Thanos C G (2005). The choroid plexus in the rise, fall and repair of the brain. BioEssays, 27(3): 262-274

Emerich D F, Vasconcellos A V, Elliott R B, Skinner S J, Borlongan C V (2004). The choroid plexus: function, pathology and therapeutic potential of its transplantation. Expert Opin Biol Ther, 4(8): 11911201

Engelhardt B, Wolburg-Buchholz K, Wolburg H (2001). Involvement of the choroid plexus in central nervous system inflammation. Microsc Res Tech, 52(1): 112-129

Falcão A M, Marques F, Novais A, Sousa N, Palha J A, Sousa J C (2012). The path from the choroid plexus to the subventricular zone: go with the flow! Front Cell Neurosci, 6: 34

Falk S, Wurdak H, Ittner L M, Ille F, Sumara G, Schmid M T, Draganova K, Lang K S, Paratore C, Leveen P, Suter U, Karlsson S, Born W, Ricci R, Götz M, Sommer L (2008). Brain area-specific effect of TGF- $\beta$ signaling on Wnt-dependent neural stem cell expansion. Cell Stem Cell, 2(5): 472-483

Forlenza O V, Diniz B S, Teixeira A L, Radanovic M, Talib L L, Rocha N P, Gattaz W F (2015). Lower cerebrospinal fluid concentration of brain-derived neurotrophic factor predicts progression from mild cognitive impairment to Alzheimer's disease. Neuromolecular Med, 17(3): 326-332

Gao L, Zhou S, Cai H, Gong Z, Zang D (2014). VEGF levels in CSF and serum in mild ALS patients. J Neurol Sci, 346(1-2): 216-220

Gato A, Alonso M I, Martín C, Carnicero E, Moro J A, De la Mano A, Fernández J M, Lamus F, Desmond M E (2014). Embryonic cerebrospinal fluid in brain development: neural progenitor control. Croat Med J, 55(4): 299-305

Gong Z, Gao L, Guo J, Lu Y, Zang D (2015). bFGF in the CSF and serum of sALS patients. Acta Neurol Scand, 132(3): 171-178
González-Marrero I, Giménez-Llort L, Johanson C E, Carmona-Calero E M, Castañeyra-Ruiz L, Brito-Armas J M, Castañeyra-Perdomo A, Castro-Fuentes R (2015). Choroid plexus dysfunction impairs betaamyloid clearance in a triple transgenic mouse model of Alzheimer's disease. Front Cell Neurosci, 9: 17

Greenwood S, Swetloff A, Wade A M, Terasaki T, Ferretti P (2008). Fgf2 is expressed in human and murine embryonic choroid plexus and affects choroid plexus epithelial cell behaviour. Cerebrospinal Fluid Res, 5(1): 20

Hébert J M, Mishina Y, McConnell S K (2002). BMP signaling is required locally to pattern the dorsal telencephalic midline. Neuron, 35(6): 1029-1041

Huang S L, Shi W, Jiao Q, He X J (2011). Change of neural stem cells in the choroid plexuses of developing rat. Int J Neurosci, 121(6): 310-315

Huang X, Ketova T, Fleming J T, Wang H, Dey S K, Litingtung Y, Chiang C (2009). Sonic hedgehog signaling regulates a novel epithelial progenitor domain of the hindbrain choroid plexus. Development, 136(15): 2535-2543

Iliff J J, Wang M, Liao Y, Plogg B A, Peng W, Gundersen G A, Benveniste H, Vates G E, Deane R, Goldman S A, Nagelhus E A, Nedergaard M (2012). A paravascular pathway facilitates CSF flow through the brain parenchyma and the clearance of interstitial solutes, including amyloid $\beta$. Sci Transl Med, 4(147): 147ra111

Itokazu Y, Kitada M, Dezawa M, Mizoguchi A, Matsumoto N, Shimizu A, Ide C (2006). Choroid plexus ependymal cells host neural progenitor cells in the rat. Glia, 53(1): 32-42

Jackson E L, Garcia-Verdugo J M, Gil-Perotin S, Roy M, QuinonesHinojosa A, VandenBerg S, Alvarez-Buylla A (2006). PDGFR $\alpha$ positive B cells are neural stem cells in the adult SVZ that form glioma-like growths in response to increased PDGF signaling. Neuron, 51(2): 187-199

Jin K, Sun Y, Xie L, Batteur S, Mao X O, Smelick C, Logvinova A, Greenberg D A (2003). Neurogenesis and aging: FGF-2 and HBEGF restore neurogenesis in hippocampus and subventricular zone of aged mice. Aging Cell, 2(3): 175-183

Jin K, Zhu Y, Sun Y, Mao X O, Xie L, Greenberg D A (2002). Vascular endothelial growth factor (VEGF) stimulates neurogenesis in vitro and in vivo. Proc Natl Acad Sci USA, 99(18): 11946-11950

Johanson C, McMillan P, Tavares R, Spangenberger A, Duncan J, Silverberg G, Stopa E (2004). Homeostatic capabilities of the choroid plexus epithelium in Alzheimer's disease. Cerebrospinal Fluid Res, 1(1): 3

Johanson C, Stopa E, Baird A, Sharma H (2011a). Traumatic brain injury and recovery mechanisms: peptide modulation of periventricular neurogenic regions by the choroid plexus-CSF nexus. J Neural Transm (Vienna), 118(1): 115-133

Johanson C, Stopa E, McMillan P, Roth D, Funk J, Krinke G (2011b). The distributional nexus of choroid plexus to cerebrospinal fluid, ependyma and brain: toxicologic/pathologic phenomena, periventricular destabilization, and lesion spread. Toxicol Pathol, 39(1): $186-212$

Johansson P A (2014). The choroid plexuses and their impact on developmental neurogenesis. Front Neurosci, 8: 340

Krizhanovsky V, Ben-Arie N (2006). A novel role for the choroid plexus in BMP-mediated inhibition of differentiation of cerebellar neural progenitors. Mech Dev, 123(1): 67-75 
Krzyzanowska A, Carro E (2012). Pathological alteration in the choroid plexus of Alzheimer's disease: implication for new therapy approaches. Front Pharmacol, 3: 75

Kunis G, Baruch K, Rosenzweig N, Kertser A, Miller O, Berkutzki T, Schwartz M (2013). IFN- $\gamma$-dependent activation of the brain's choroid plexus for CNS immune surveillance and repair. Brain, 136 (Pt 11): 3427-3440

Lehtinen M K, Zappaterra M W, Chen X, Yang Y J, Hill A D, Lun M, Maynard T, Gonzalez D, Kim S, Ye P, D'Ercole A J, Wong E T, LaMantia A S, Walsh C A (2011). The cerebrospinal fluid provides a proliferative niche for neural progenitor cells. Neuron, 69(5): 893905

Li Y, Chen J, Chopp M (2002). Cell proliferation and differentiation from ependymal, subependymal and choroid plexus cells in response to stroke in rats. J Neurol Sci, 193(2): 137-146

Licht T, Eavri R, Goshen I, Shlomai Y, Mizrahi A, Keshet E (2010). VEGF is required for dendritogenesis of newly born olfactory bulb interneurons. Development, 137(2): 261-271

Liddelow S A (2015). Development of the choroid plexus and bloodCSF barrier. Front Neurosci, 9: 32

Lun M P, Monuki E S, Lehtinen M K (2015). Development and functions of the choroid plexus-cerebrospinal fluid system. Nat Rev Neurosci, 16(8): 445-457

Mackenzie F, Ruhrberg C (2012). Diverse roles for VEGF-A in the nervous system. Development, 139(8): 1371-1380

Maharaj A S R, Walshe T E, Saint-Geniez M, Venkatesha S, Maldonado A E, Himes N C, Matharu K S, Karumanchi S A, D'Amore P A (2008). VEGF and TGF- $\beta$ are required for the maintenance of the choroid plexus and ependyma. J Exp Med, 205 (2): 491-501

Maisonpierre P C, Belluscio L, Friedman B, Alderson R F, Wiegand S J, Furth M E, Lindsay R M, Yancopoulos G D (1990). NT-3, BDNF, and NGF in the developing rat nervous system: parallel as well as reciprocal patterns of expression. Neuron, 5(4): 501-509

Marques F, Sousa J C, Coppola G, Gao F, Puga R, Brentani H, Geschwind D H, Sousa N, Correia-Neves M, Palha J A (2011). Transcriptome signature of the adult mouse choroid plexus. Fluids Barriers CNS, 8(1): 10

Mashayekhi F, Azari M, Moghadam L M, Yazdankhah M, Naji M, Salehi Z (2009). Changes in cerebrospinal fluid nerve growth factor levels during chick embryonic development. J Clin Neurosci, 16 (10): 1334-1337

Mashayekhi F, Sadeghi M, Rajaei F (2011). Induction of perlecan expression and neural cell proliferation by FGF-2 in the developing cerebral cortex: an in vivo study. J Mol Neurosci, 45(2): 87-93

McCoy M K, Tansey M G (2008). TNF signaling inhibition in the CNS: implications for normal brain function and neurodegenerative disease. J Neuroinflammation, 5(1): 45

Meeker R B, Williams K, Killebrew D A, Hudson L C (2012). Cell trafficking through the choroid plexus. Cell Adhes Migr, 6(5): 390396

Mesquita S D, Ferreira A C, Gao F, Coppola G, Geschwind D H, Sousa J C, Correia-Neves M, Sousa N, Palha J A, Marques F (2015). The choroid plexus transcriptome reveals changes in type I and II interferon responses in a mouse model of Alzheimer's disease. Brain Behav Immun, 49: 280-292

Miyan J A, Nabiyouni M, Zendah M (2003). Development of the brain: a vital role for cerebrospinal fluid. Can J Physiol Pharmacol, 81(4): 317-328

Moore L, Bain J M, Loh J M, Levison S W (2014). PDGF-responsive progenitors persist in the subventricular zone across the lifespan. ASN Neuro, 6(2): 65-81

Nielsen C M, Dymecki S M (2010). Sonic hedgehog is required for vascular outgrowth in the hindbrain choroid plexus. Dev Biol, 340 (2): $430-437$

Nilsson C, Hultberg B M, Gammeltoft S (1996). Autocrine role of insulin-like growth factor II secretion by the rat choroid plexus. Eur J Neurosci, 8(3): 629-635

Pencea V, Bingaman K D, Freedman L J, Luskin M B (2001). Neurogenesis in the subventricular zone and rostral migratory stream of the neonatal and adult primate forebrain. Exp Neurol, 172(1): 116

Pillai A, Kale A, Joshi S, Naphade N, Raju M S V K, Nasrallah H, Mahadik S P (2010). Decreased BDNF levels in CSF of drug-naive first-episode psychotic subjects: correlation with plasma BDNF and psychopathology. Int J Neuropsychopharmacol, 13(4): 535-539

Prasongchean W, Vernay B, Asgarian Z, Jannatul N, Ferretti P (2015). The neural milieu of the developing choroid plexus: neural stem cells, neurons and innervation. Front Neurosci, 9: 103

Preston J E (2001). Ageing choroid plexus-cerebrospinal fluid system. Microsc Res Tech, 52(1): 31-37

Rabie M A, Mohsen M, Ibrahim M, El-Sawy Mahmoud R (2014). Serum level of brain derived neurotrophic factor (BDNF) among patients with bipolar disorder. J Affect Disord, 162: 67-72

Redzic Z B, Preston J E, Duncan J A, Chodobski A, SzmydyngerChodobska J (2005). "The Choroid Plexus - Cerebrospinal Fluid System: From Development to Aging," in Current Topics in Developmental Biology, ed. Gerald P. Schatten (Academic Press), 1-52. Available at: http://www.sciencedirect.com/science/article/pii/ S0070215305710012 [Accessed November 15, 2013].

Redzic Z B, Segal M B (2004). The structure of the choroid plexus and the physiology of the choroid plexus epithelium. Adv Drug Deliv Rev, 56(12): 1695-1716

Ruiz de Almodovar C, Coulon C, Salin P A, Knevels E, Chounlamountri N, Poesen K, Hermans K, Lambrechts D, Van Geyte K, Dhondt J, Dresselaers T, Renaud J, Aragones J, Zacchigna S, Geudens I, Gall D, Stroobants S, Mutin M, Dassonville K, Storkebaum E, Jordan B F, Eriksson U, Moons L, D’Hooge R, Haigh J J, Belin M F, Schiffmann S, Van Hecke P, Gallez B, Vinckier S, Chédotal A, Honnorat J, Thomasset N, Carmeliet P, Meissirel C (2010). Matrix-binding vascular endothelial growth factor (VEGF) isoforms guide granule cell migration in the cerebellum via VEGF receptor Flk1. J Neurosci, 30(45): 15052-15066

Salehi Z, Mashayekhi F, Naji M, Pandamooz S (2009). Insulin-like growth factor-1 and insulin-like growth factor binding proteins in cerebrospinal fluid during the development of mouse embryos. J Clin Neurosci, 16(7): 950-953

Sathyanesan M, Girgenti M J, Banasr M, Stone K, Bruce C, Guilchicek E, Wilczak-Havill K, Nairn A, Williams K, Sass S, Duman J G, Newton S S (2012). A molecular characterization of the choroid plexus and stress-induced gene regulation. Transl Psychiatry, 2(7): e139

Saunders N R, Daneman R, Dziegielewska K M, Liddelow S A 
(2013). Transporters of the blood-brain and blood-CSF interfaces in development and in the adult. Mol Aspects Med, 34(2-3): 742-752

Schänzer A, Wachs F P, Wilhelm D, Acker T, Cooper-Kuhn C, Beck H, Winkler J, Aigner L, Plate K H, Kuhn H G (2004). Direct stimulation of adult neural stem cells in vitro and neurogenesis in vivo by vascular endothelial growth factor. Brain Pathol, 14(3): 237-248

Scola G, Andreazza A C (2015). The role of neurotrophins in bipolar disorder. Prog Neuropsychopharmacol Biol Psychiatry, 56: 122-128

Segklia A, Seuntjens E, Elkouris M, Tsalavos S, Stappers E, Mitsiadis T A, Huylebroeck D, Remboutsika E, Graf D (2012). Bmp7 regulates the survival, proliferation, and neurogenic properties of neural progenitor cells during corticogenesis in the mouse. PLoS ONE, 7(3): e34088

Serot J M, Béné M C, Foliguet B, Faure G C (1997). Altered choroid plexus basement membrane and epithelium in late-onset Alzheimer's disease: an ultrastructural study. Ann N Y Acad Sci, 826(1 Cerebrovascul): 507-509

Serot J M, Foliguet B, Béné M C, Faure G C (2001). Choroid plexus and ageing in rats: a morphometric and ultrastructural study. Eur J Neurosci, 14(5): 794-798

Spatazza J, Lee H H C, Di Nardo A A, Tibaldi L, Joliot A, Hensch T K, Prochiantz A (2013). Choroid-plexus-derived Otx2 homeoprotein constrains adult cortical plasticity. Cell Reports, 3(6): 1815-1823

Spector R, Johanson C E (2010). Vectorial ligand transport through mammalian choroid plexus. Pharm Res, 27(10): 2054-2062

Spector R, Keep R F, Robert Snodgrass S, Smith Q R, Johanson C E (2015a). A balanced view of choroid plexus structure and function: Focus on adult humans. Exp Neurol, 267: 78-86

Spector R, Robert Snodgrass S, Johanson C E (2015b). A balanced view of the cerebrospinal fluid composition and functions: Focus on adult humans. Exp Neurol, 273: 57-68

Stolp H B, Molnár Z (2015). Neurogenic niches in the brain: help and hindrance of the barrier systems. Front Neurosci, 9: 20

Storkebaum E, Carmeliet P (2004). VEGF: a critical player in neurodegeneration. J Clin Invest, 113(1): 14-18

Strazielle N, Mutin M, Ghersi-Egea J F (2005). Les plexus choroïdes: une interface dynamique entre sang et liquide cephalo-rachidien. Morphologie, 89(285): 90-101

Strelau J, Sullivan A, Böttner M, Lingor P, Falkenstein E, Suter-
Crazzolara C, Galter D, Jaszai J, Krieglstein K, Unsicker K (2000). Growth/differentiation factor-15/macrophage inhibitory cytokine-1 is a novel trophic factor for midbrain dopaminergic neurons in vivo. $\mathrm{J}$ Neurosci, 20(23): 8597-8603

Tochitani S, Kondo S (2013). Immunoreactivity for GABA, GAD65, GAD67 and Bestrophin-1 in the meninges and the choroid plexus: implications for non-neuronal sources for GABA in the developing mouse brain. PLoS ONE, 8(2): e56901

Turner C A, Thompson R C, Bunney W E, Schatzberg A F, Barchas J D, Myers R M, Akil H, Watson S J (2014). Altered choroid plexus gene expression in major depressive disorder. Front Hum Neurosci, 8: 238

Vaccarino F M, Schwartz M L, Raballo R, Nilsen J, Rhee J, Zhou M, Doetschman T, Coffin J D, Wyland J J, Hung Y T (1999). Changes in cerebral cortex size are governed by fibroblast growth factor during embryogenesis. Nat Neurosci, 2(3): 246-253

Wagner J P, Black I B, DiCicco-Bloom E (1999). Stimulation of neonatal and adult brain neurogenesis by subcutaneous injection of basic fibroblast growth factor. J Neurosci, 19(14): 6006-6016

Watanabe M, Kang Y J, Davies L M, Meghpara S, Lau K, Chung C Y, Kathiriya J, Hadjantonakis A K, Monuki E S (2012). BMP4 sufficiency to induce choroid plexus epithelial fate from embryonic stem cell-derived neuroepithelial progenitors. J Neurosci, 32(45): 15934-15945

Werner H, LeRoith D (2014). Insulin and insulin-like growth factor receptors in the brain: physiological and pathological aspects. Eur Neuropsychopharmacol, 24(12): 1947-1953

Xia Y X, Ikeda T, Xia X Y, Ikenoue T (2000). Differential neurotrophin levels in cerebrospinal fluid and their changes during development in newborn rat. Neurosci Lett, 280(3): 220-222

Zappaterra M W, Lehtinen M K (2012). The cerebrospinal fluid: regulator of neurogenesis, behavior, and beyond. Cell Mol Life Sci, 69(17): 2863-2878

Ziegler A N, Levison S W, Wood T L (2015). Insulin and IGF receptor signalling in neural-stem-cell homeostasis. Nat Rev Endocrinol, 11 (3): $161-170$

Ziegler A N, Schneider J S, Qin M, Tyler WA, Pintar J E, Fraidenraich D, Wood T L, Levison S W (2012). IGF-II promotes stemness of neural restricted precursors. Stem Cells, 30(6): 1265-1276 